\title{
The relationship between pruning and the incidence of Neonectria fuckeliana in Pinus radiata
}

\author{
Tod D Ramsfield ${ }^{1,2^{*}}$, Matthew WP Power ${ }^{1,3}$ and Mark O Kimberley ${ }^{1}$
}

\begin{abstract}
Background: Nectria flute canker is an important disease of Pinus radiata in the South Island of New Zealand. The causal agent of the disease, Neonectria fuckeliana, is a known wound invader of Picea abies in Europe. To test the hypothesis that pruning wounds are necessary for infection of Pinus radiata by N. fuckeliana, the presence of the fungus was assessed in pruned and unpruned trees.

Methods: The presence of the fungus was investigated in a total of 180 trees (90 pruned and 90 unpruned) using both DNA and microbial culturing techniques over three consecutive years. The data was analysed using a logistic regression analysis.

Results: It was found that there was no significant difference in the presence of the fungus in pruned and unpruned trees. Conclusions: These results indicate that pruning wounds are not the primary infection court for N. fuckeliana and that the fungus is able to enter the tree through an alternative infection point.
\end{abstract}

Keywords: Neonectria fuckeliana; Pinus radiata; Nectria flute canker disease

\section{Background}

Nectria flute canker disease was first discovered affecting Pinus radiata D. Don in the Otago region of the South Island of New Zealand in the mid 1990s (Dick and Crane 2009). The disease is characterised by elongated cankers that extend up and down the trunk from pruning wounds, occasionally resulting in extreme stem malformation (Crane et al. 2009; Gadgil et al. 2003). The causal agent of this disease was proven by Koch's postulates to be Neonectria fuckeliana (C. Booth) Castl. \& Rossman (syn. Nectria fuckeliana C. Booth) (Dick and Crane 2009). Recently, Nectria flute canker disease has been reported on Pinus radiata in Chile (Morales 2009).

Neonectria fuckeliana has been found to infect wounds on Picea abies (L.) Karst following pruning in Germany (Metzler 1997), wounding by moose (Alces alces L.) in Sweden (Vasiliauskas et al. 1996) and mechanical wounds in Norway (Roll-Hansen and Roll-Hansen 1980) and Lithuania (Vasiliauskas and Stenlid 1998). Although $N$. fuckeliana was found to be the most common wound

\footnotetext{
* Correspondence: Tod.Ramsfield@NRCan-RNCan.gc.ca

${ }^{1}$ Scion (New Zealand Forest Research Institute Ltd.), Private Bag 3020,

Rotorua 3010, New Zealand

${ }^{2}$ Current address: Natural Resources Canada, Canadian Forest Service, Northern Forestry Centre, 5320122 St, Edmonton, AB T6H 3S5, Canada Full list of author information is available at the end of the article
}

invader in these studies, the fungus does not induce disease (Vasiliauskas et al. 1996) as it does in Pinus radiata. However, Neonectria fuckeliana has been implicated in a canker disease of Abies concolor (Gord. \& Glend.) Lindl. in California (Schultz and Parmeter 1990). In addition to wounded trees, the fungus has also been recovered from sound wood. Metzler (1997) recovered $N$. fuckeliana from Picea abies that had not been pruned, Huse (1981) isolated N. fuckeliana from sound Picea abies on highly productive sites in Norway, and Vasiliauskas and Stenlid (1998) found no significant difference in the presence of $N$. fuckeliana in wounded and sound Picea abies in Lithuania. It is possible that the fungus colonised a wound that later closed (Huse 1981), or entered the stem through dead branch stubs (Vasiliauskas and Stenlid 1998).

Pruning to promote clear wood is an important component of the silvicultural regime of Pinus radiata (Neilsen and Pinkard 2003); however, this silvicultural investment can be negated in pruned trees exhibiting the symptoms of flute canker disease (Hopkins et al. 2012). It has been shown that $N$. fuckeliana is commonly associated with wounds, including pruning wounds, in European specimens of Picea abies (Metzler 1997). In New Zealand, flute canker disease is associated with 
pruning wounds on Pinus radiata (Gadgil et al. 2003; Hopkins et al. 2012). Pruning wounds have been demonstrated to be important infection courts for Sphaeropsis sapinea (Fr.) Dyko \& B. Sutton, causal agent of Diplodia whorl canker, another important canker disease of Pinus radiata (Chou and MacKenzie 1988), and for Seiridium cardinale (W.W. Wagner) B. Sutton \& I.A.S. Gibson and $S$. cupressi (Guba) Boesew. that infect pruning wounds on Cupressus macrocarpa Gordon \& Leyland in New Zealand (Hood et al. 2009). Understanding the relationship between pruning and the presence of $N$. fuckeliana has important management implications; therefore, the objective of this study was to investigate the hypothesis that pruning wounds are the primary infection court for $N$. fuckeliana in Pinus radiata in New Zealand. This was accomplished by assessing the presence of the pathogen in pruned and unpruned trees.

\section{Methods}

\section{Sampling}

A total of 180 trees were selected from four different forest stands in the Otago region of New Zealand in 2006. In each stand, an equal number of pruned and unpruned trees of the same cohort were selected for sampling. Stand 1 was planted in 1997 (40 trees sampled), stand 2 in 1998 (40 trees sampled), stand 3 in 2000 (50 trees sampled), and stand 4 in 2002 (50 trees sampled). Stands 1 and 2 had been pruned 4-5 months prior to the first assessment in February 2006, while Stand 3 had been pruned 18 months prior to the first assessment. Stand 4 had two pruning lifts, 25 and 11 months prior to the first assessment. Two pruned and six unpruned trees were accidently removed in a thinning operation midway through the trial, and these trees were therefore not included in the analysis. At the end of the study in 2008, all trees were classified as either fluted or unfluted based on the presence of depressions in the stem in 2008 that it was believed might later develop into flute cankers, given that trees were generally too young in the study for fully developed flute cankers (as illustrated by Bulman 2007) to be present.

Samples were collected from trees using an increment borer that removed $5 \mathrm{~mm}$ diameter cores. The increment corer was surface sterilised in bleach and rinsed with commercially bottled water between every tree to avoid cross contamination. To sample pruned trees, the increment corer was inserted directly above a branch stub while unpruned trees were sampled as close to the whorl as possible. The same trees were sampled in 2006, 2007 and 2008.

\section{Detection of Neonectria fuckeliana infection}

The presence of $N$. fuckeliana in the samples was determined using visual identification of microbial cultures and also using DNA-based methods. To culture $N$. fuckeliana a $5 \mathrm{~mm}$ sample was cut from each core, surface sterilised in $70 \%$ ethanol, followed by rinsing in 10\% bleach and three rinses in sterile distilled water, all for 30 seconds per step. The pieces of wood were then placed on $2 \%$ malt extract agar (MEA) and incubated at $20^{\circ} \mathrm{C}$ in the dark. Mycelial growth that emerged from the wood sample was subcultured onto fresh MEA and N. fuckeliana was identified visually, based on the morphological characteristics of the Acremonium anamorph. Microbiological culturing was only conducted on samples collected in 2007 and 2008.

The presence of N. fuckeliana was assessed for all samples using the PCR method of Langrell (2005). Ten small disks were randomly cut from the length of the increment core and then ground in liquid nitrogen using a mortar and pestle. A FastDNA Kit (with extraction buffers CLS-VR and PPS) and a FastPrep instrument (Qbiogene Inc, CA) were used to extract DNA from a volume of 200-500 $\mu \mathrm{l}$ of ground tissue following the manufacturer's protocol. Homogenization was carried out using lysing matrix A at speed 5 for 20 seconds, repeated 3 times, with a 2 minute incubation on ice between 20 second bursts. Following DNA extraction, the concentration of DNA in every sample was measured using a FLUOstar Galaxy fluorometer (BMG Lab Technologies) and then diluted to a concentration of $1 \mathrm{ng} / \mu \mathrm{l}$ with sterile water for PCR analysis.

The DNA of N. fuckeliana was detected using a nestedPCR protocol, which used the universal ITS primers ITS-1F (5' -CTT GGT CAT TTA GAG GAA GTA A-3') (Gardes and Bruns 1993) and ITS-4 (5'-TCC TCC GCT TAT TGA TAT GC-3') (White et al. 1990) to amplify all fungal DNA within the sample. The PCR products were then subjected to a second round of PCR using the $N$. fuckeliana specific PCR primers Cct1 (5'-ACC CCA AAC CCT TAT TTC TG-3') and Cct2 (5'-ACG GCG TGG CCG CGC CGC TT-3') developed by Langrell (2005). The first round of PCR was carried out in a $15 \mu \mathrm{l}$ reaction volume, containing $2.5 \mathrm{ng}$ of template DNA, $0.05 \mathrm{pmol} / \mu \mathrm{l}$ of PCR primers ITS-1F and ITS-4, $0.45 \mathrm{U}$ Taq DNA polymerase (Roche), $1 \mathrm{x}$ reaction buffer (Roche), $1.5 \mathrm{mM} \mathrm{MgCl} 2,0.2 \mathrm{mM}$ each of dATP, dGTP, $\mathrm{dCTP}$, and dTTP (Roche). The PCR conditions were $95^{\circ} \mathrm{C}$ for $6 \mathrm{~min}$, followed by 35 cycles of $95^{\circ} \mathrm{C}$ for $30 \mathrm{~s}, 60^{\circ} \mathrm{C}$ for $40 \mathrm{~s}, 72^{\circ} \mathrm{C}$ for $40 \mathrm{~s}$, and then one cycle of $72^{\circ} \mathrm{C}$ for $5 \mathrm{~min}$ and a $4^{\circ} \mathrm{C}$ hold. The PCR reaction contents of the second round reaction were the same as the first round, but the $N$. fuckeliana PCR primers were used and 1:50 dilution of the first-round PCR products were used as the DNA template for the second round PCR reaction. The second round PCR profile was $94^{\circ} \mathrm{C}$ for $3 \mathrm{~min}$, followed by 30 cycles of $94^{\circ} \mathrm{C}$ for $1 \mathrm{~min}, 62^{\circ} \mathrm{C}$ for $1 \mathrm{~min}, 72^{\circ} \mathrm{C}$ for 1 min, then one cycle of $72^{\circ} \mathrm{C}$ for $10 \mathrm{~min}$ and a $4{ }^{\circ} \mathrm{C}$ hold. 
Prior to use in this study, a pilot study was conducted using DNA from fungi that are commonly isolated from Pinus radiata to ensure that the test was specific to $N$. fuckeliana. Additionally, the amplicon from $N$. fuckeliana was sequenced to validate the assumption that a band of 360 base pairs was diagnostic for the presence of N. fuckeliana.

Products obtained from the PCR procedure were subjected to electrophoresis on $1 \%$ agarose gels, stained with ethidium bromide and visualised and photographed under UV light. If a band of 360 base pairs was present following the second round PCR reaction, it was assumed that $N$. fuckeliana DNA was present in the sample and the sample was thus scored as $N$. fuckeliana positive. The PCR test was repeated on all samples that gave an initial positive result to confirm the initial positive result.

\section{Statistical analysis}

A logistic regression analysis was performed to test for a difference in the presence or absence of $N$. fuckeliana between pruned and unpruned trees. In this analysis, a tree was considered to be infected with $N$. fuckeliana if the fungus was either isolated by culturing or detected by the PCR test in any of the three years. The following logistic regression model was fitted using the SAS (Version 9.2) procedure GENMOD:

$$
\mathrm{y}=\operatorname{logit}(\text { intercept }+ \text { stand }+ \text { pruning }),
$$

where y was a binary variable coded as 1 for infected trees and 0 for uninfected trees. An analysis of deviance associated with this model, with the variance scaled to allow for overdispersion, was used to determine significance of pruning in relation to the presence of $N$. fuckeliana.

To test whether stems with early evidence of fluting were more likely to be infected, a further term was added to the model:

$$
\mathrm{y}=\text { logit (intercept }+ \text { stand }+ \text { pruning }+ \text { fluting) }
$$

To assess change in infection rates over time, and to determine whether this varied between pruned and unpruned trees, a Generalised Estimation Equation (GEE) model was fitted using PROC GENMOD. For this analysis a binary variable, $y$, representing presence of $N$. fuckeliana detected by the PCR method in each assessment year was the dependent variable. The model was of the following form:

$$
\begin{aligned}
y= & \text { logit }(\text { intercept }+ \text { stand }+ \text { pruning }+ \text { year } \\
& + \text { stand } \times \text { year }+ \text { pruning } \times \text { year })
\end{aligned}
$$

This model was used to test for any change in infection level within each tree over the course of the study and used an unstructured covariance structure between assessment years.

\section{Results}

Neonectria fuckeliana was detected within both pruned and unpruned Pinus radiata in all years (Table 1). When the results from all three annual assessments were pooled, the total number of trees found to be infected in at least one assessment was 82 , or $47.7 \%$. Most infected trees were detected using the PCR technique, with 80 (38 unpruned and 42 pruned) being detected using PCR, and 17 (8 unpruned and 9 pruned) being detected using culturing, and with only 2 infected trees being detected solely by culturing. The presence of $N$. fuckeliana was detected within pruned and fluted Pinus radiata (Figure 1), as well as unpruned and non-fluted Pinus radiata (Figure 2). Perithecia of $N$. fuckeliana were observed on only 1 tree in 2006, which was found to be dead in 2007.

The analysis of deviance of the logistic regression model of the total incidence of infection per tree across the course of the study indicated no significant difference in $N$. fuckeliana infection between pruned and unpruned trees $\left(\mathrm{F}_{1,167}=0.24, \mathrm{p}=0.62\right.$; Figure $\left.3 \mathrm{a}\right)$. There was a significant difference in the presence of the fungus in the different stands $\left(\mathrm{F}_{3,167}=10.24, \mathrm{p}<0.0001\right)$ with the fungus being more abundant in the older stands (Stands 1 and 2). There was no significant difference between trees showing evidence of fluting and those with no fluting $\left(\mathrm{F}_{1,160}=2.04, \mathrm{p}=0.15\right.$; Figure $\left.3 \mathrm{~b}\right)$.

The development of infection through time over the 3 -year course of the study was analysed using a GEE model. There was no significant difference in infection rate between pruned and unpruned trees $\left(\chi_{1}^{2}=0.46, \mathrm{p}=0.50\right)$, and no significant interaction between assessment year and pruning $\left(\chi_{2}^{2}=4.52, \mathrm{p}=0.10\right)$. The mean infection rates for pruned and unpruned trees at each assessment showed some evidence of an increase in infection in pruned relative to unpruned trees over the course of the study (Figure 4). However, the lack of a significant

\begin{tabular}{|c|c|c|c|c|c|c|}
\hline Neonectria fuckeliana presence & 2006 pruned & 2006 unpruned & 2007 pruned & 2007 unpruned & 2008 pruned & 2008 unpruned \\
\hline Positive & 0.21 & 0.24 & 0.19 & 0.24 & 0.27 & 0.24 \\
\hline Negative & 0.79 & 0.76 & 0.81 & 0.76 & 0.73 & 0.76 \\
\hline
\end{tabular}
interaction between pruning and assessment year in the

Table 1 Frequency of Neonectria fuckeliana occurrence in pruned and unpruned Pinus radiata (all stands combined, PCR and culturing results pooled) 


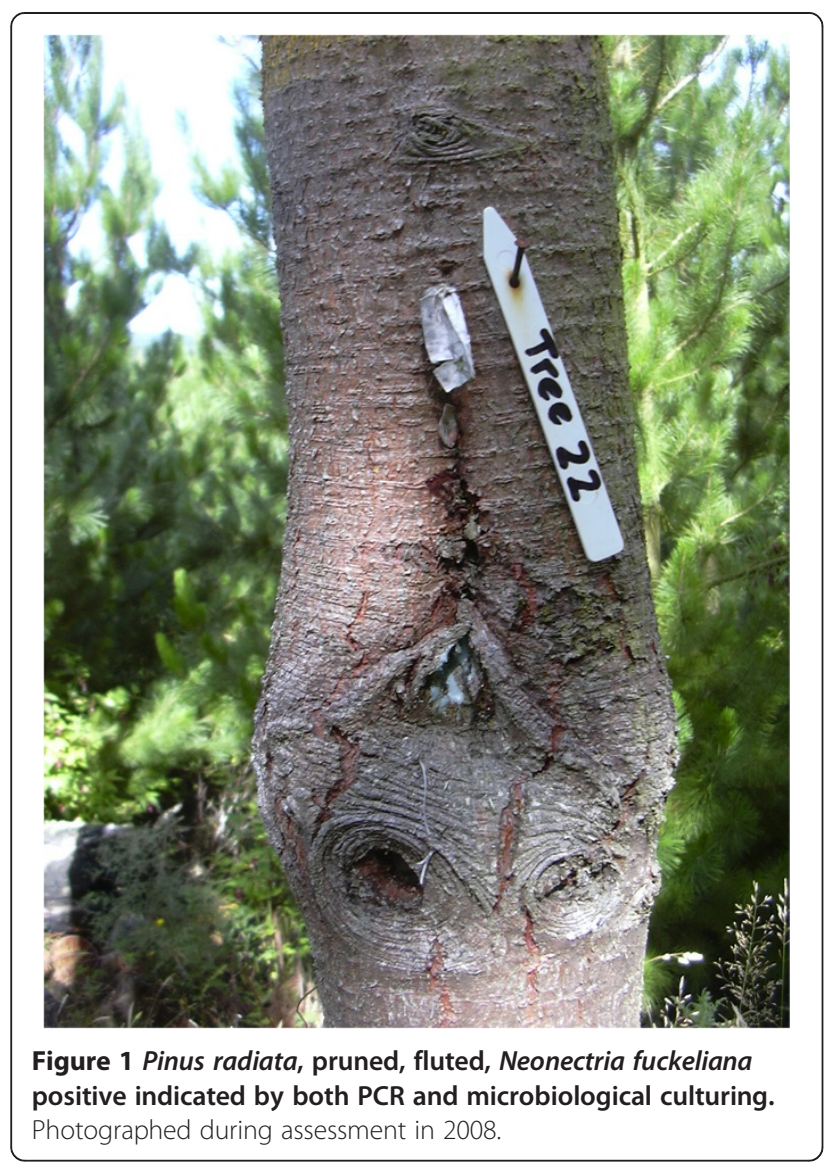

GEE model indicates that this result is not statistically significant. A specific test of the difference of differences in infection between pruned and unpruned trees at the start and end of the study provided some limited evidence of an increase in infection in pruned relative to unpruned trees $\left(\chi_{1}^{2}=3.26, \mathrm{p}=0.071\right)$.

The GEE model indicated there was a significant interaction between assessment year and stand $\left(\chi_{6}^{2}=27.49, p=0.0001\right)$ with infection increasing during the 3-year study in the two younger stands but decreasing in the two older stands (Figure 5). The mean infection rate per tree totalled over the 3 years of the study (e.g., Figures $3 \mathrm{a} \& 3 \mathrm{~b}$ ) is higher than the rates for each year (Figures $4 \& 5$ ) because $N$. fuckeliana was not always sampled from a positive tree at every assessment. Some trees were negative for $N$. fuckeliana at the first assessment and were then positive in the following years. Some trees that were found to be positive in one year did not yield a positive test result the following year, presumably because the increment core borer sampled an area of the stem that was not colonised by the fungus.

\section{Discussion}

Nectria flute canker, caused by N. fuckeliana (Dick and Crane 2009), is an important disease of Pinus radiata

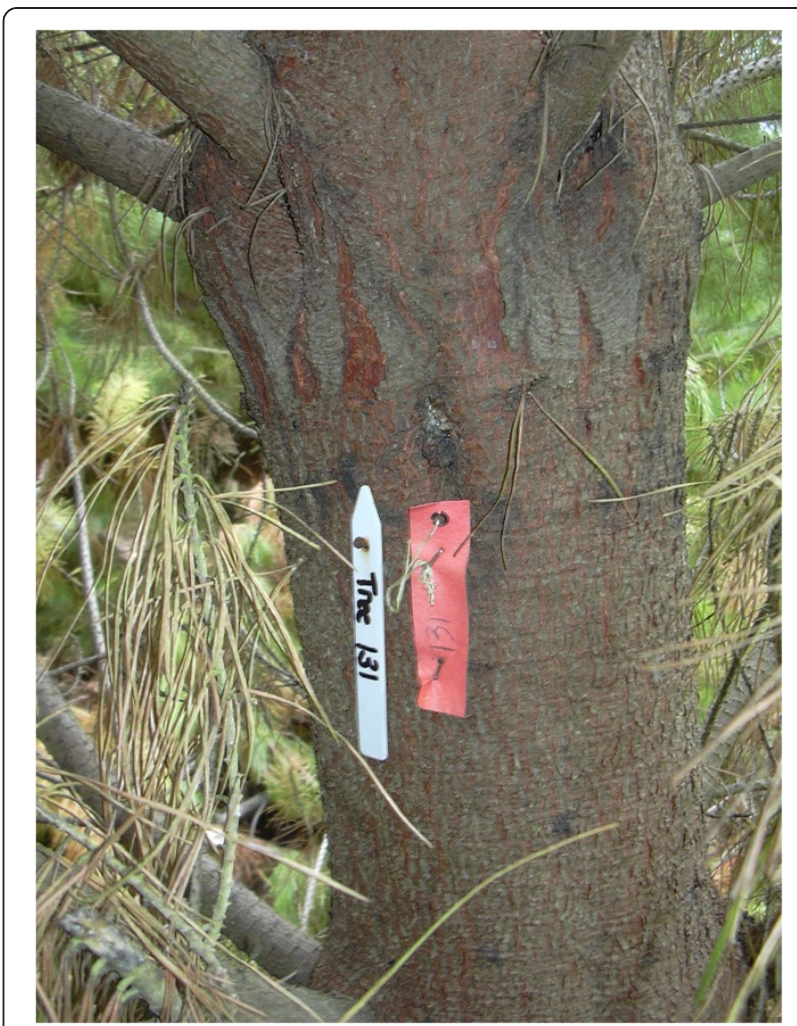

Figure 2 Pinus radiata, unpruned, no fluting, Neonectria fuckeliana positive indicated by both PCR and microbiological culturing. Photographed during assessment in 2008.

in New Zealand (Gadgil 2003) and Chile (Morales 2009). The flute canker disease is associated with pruning wounds (Gadgil 2003; Hopkins et al. 2012; Morales 2009) and the fungus has been found in wounded tissue of Picea abies in Europe (Huse 1981; Metzler 1997; Roll-Hansen and Roll-Hansen 1979, 1980; Vasiliauskas and Stenlid 1998; Vasiliauskas et al. 1996); therefore, it

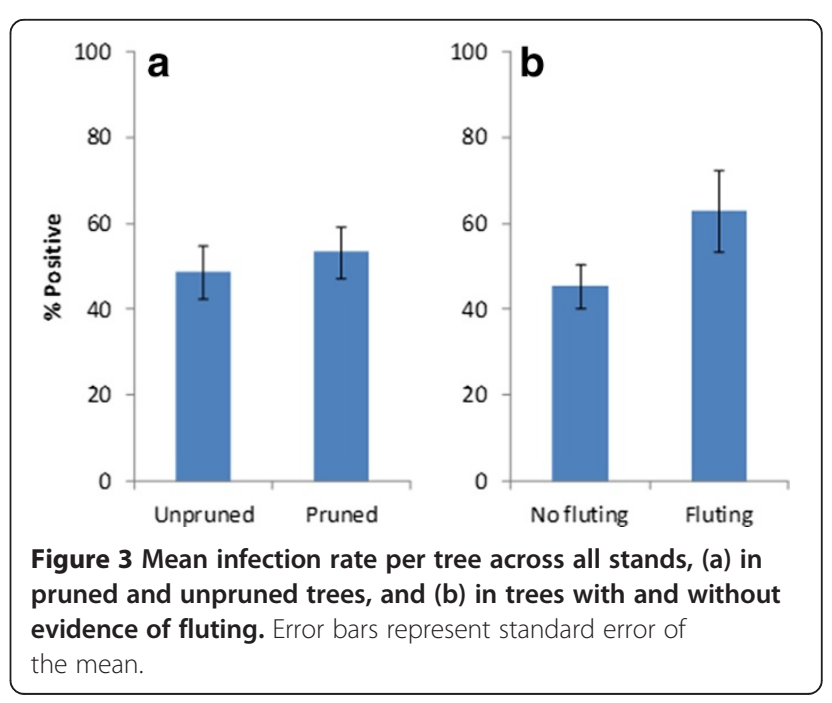




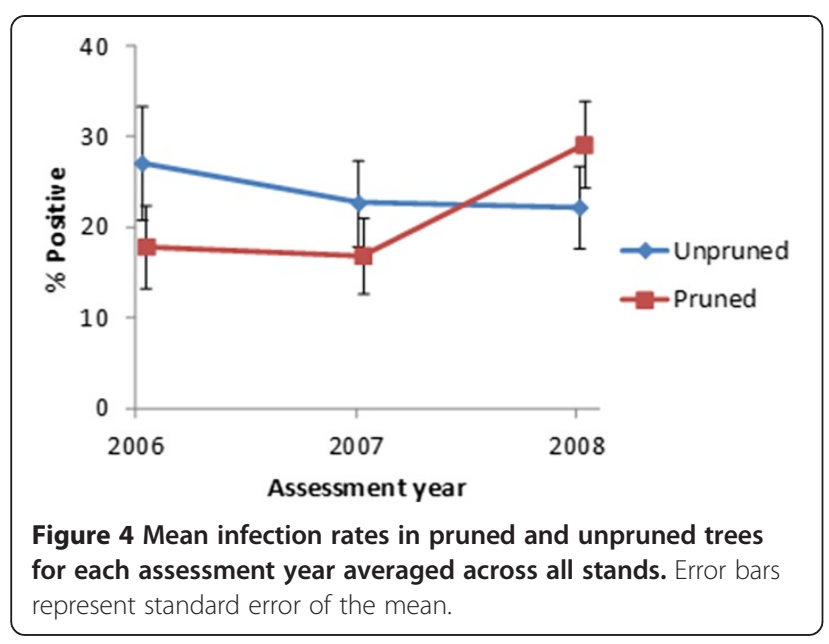

was hypothesised that pruning wounds serve as the primary infection courts for $N$. fuckeliana in Pinus radiata. In this study, we assessed the presence of $N$. fuckeliana in pruned and unpruned Pinus radiata and the results indicated that pruning wounds are not the primary infection courts for the pathogen. There was no significant difference of the presence of the fungus in pruned and unpruned trees. These results do not rule out pruning wounds as infection courts for $N$. fuckeliana, and this study provides some limited evidence of an increasing level of infection in pruned versus unpruned trees over the course of the study (Figure 4). However, the similar level of infection between pruned and unpruned trees (Figure 3a) suggests that the fungus is able to enter Pinus radiata via other routes, and demonstrates that pruning wounds are not the only infection courts or even the primary infection courts for the fungus. Despite this result, field evidence indicates that the development of Nectria flute canker disease is closely associated with pruning (Bulman 2007).

Hopkins et al. (2012) inoculated stems and pruning wounds on Pinus radiata with both the ascospores of $N$.

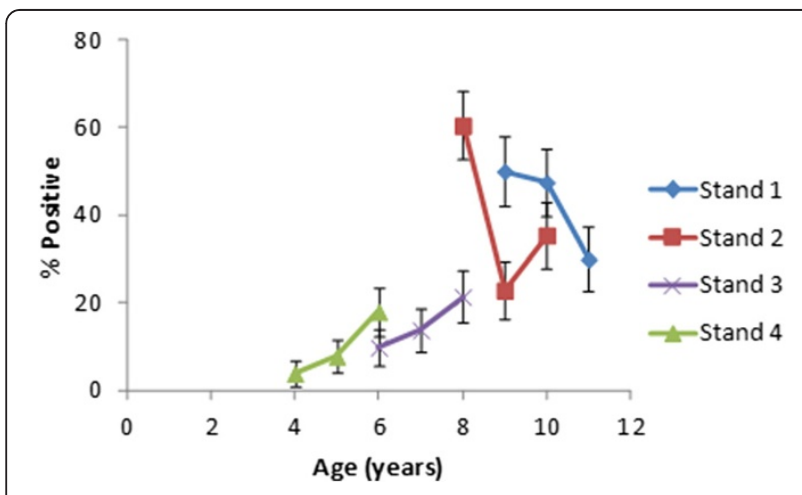

Figure 5 Mean infection rates by stand for each assessment year averaged across both pruned and unpruned trees. Error bars represent standard error of the mean. fuckeliana and conidia of the Acremonium anamorph of $N$. fuckeliana. Results of these studies indicated that deep stem wounds resulted in significantly more flute canker than shallow wounds or inoculated pruning wounds and that deep wounds allowed the pathogen to spread more readily within the stem. It was found that inoculation of the pruned branch stubs did not result in extensive disease development as the fungus remained contained within the branch trace and did not readily colonise the sapwood. The authors also noted a high degree of heterogeneity within the inoculated trees, suggesting that the defense response to $N$. fuckeliana within Pinus radiata in New Zealand is variable.

Neonectria fuckeliana has been recovered from sound Picea abies (Huse 1981; Metzler 1997; Vasiliauskas and Stenlid 1998) although Huse (1981) postulated that the fungus infected a wound that had since closed and Vasiliauskas and Stenlid (1998) suggested infected branch stubs may be an important infection court. A similar mode of infection has been proposed for Echinodontium tinctorium (Ellis \& Everh.) Ellis \& Everh., the Indian paint fungus, which causes heart rot of western hemlock (Tsuga heterophylla (Raf.) Sarg.). Basidiospores of the fungus colonise 1-2 $\mathrm{mm}$ diameter branchlet stubs that later close over, thus including the basidiospores within the stem. The fungus can then lie dormant for up to 50 years, until activated by host stressors, such as large branch stubs, logging injury, a broken top, or stress cracks, that leads to the initiation of decay (Etheridge and Craig 1976). A similar situation may be occurring in $N$. fuckeliana infected Pinus radiata. It is also possible that the fungus is able to enter the tree through an alternate infection court, such as cracks in the bark at the branch collar or crotch (Hopkins et al. 2012), become established within the sound stem and then actively incite disease following pruning.

The results from this study show that $N$. fuckeliana may be present in sound Pinus radiata, although previous studies have found that Nectria flute canker disease is associated with pruned trees (Gadgil et al. 2003; Bulman 2007; Hopkins et al. 2012). As pruning can be an important component of Pinus radiata silviculture (Neilsen and Pinkard 2003), early studies were directed at understanding the relationship between pruning and disease development in order to manage the disease (Bulman 2007). Bulman (2009) showed that winter pruning and pruning stubs greater than $60 \mathrm{~mm}$ in diameter resulted in greater disease development. The trial was initially established to assess the effect of season of pruning on disease development, whether fungicides can protect branch stubs and the length of time that branch stubs are susceptible to infection (Bulman 2007, 2009); thus, it was hypothesised that pruning wounds were the primary infection court for the fungus. The current study indicates 
that the fungus is able to become established in the tree in the absence of pruning wounds, and it is therefore possible that disease development is related to pruning stress. To further understand the interactions between pruning stress and disease development, a separate trial has been established in which 180 trees were pruned to induce a stress response. The presence of the fungus within a small percentage of the trees in this new trial at the time of pruning has been verified using the DNA method (data not shown) but flute canker disease symptoms have yet to be observed two years following trial establishment. It is our intent to publish the results of this trial separately.

Neonectria fuckeliana is able to colonise pruning wounds (Hopkins et al. 2012), likely by rain splashed ascospores (Crane et al. 2009), and this study has not ruled out pruning wounds as infection courts. Hopkins et al. (2012) showed that the response of an individual tree to artificial inoculation is highly variable; therefore, host response also has an important role in disease development. The suggestions of Crane et al. (2009) to adjust spacing in such a way as to reduce humidity within the stand, and Bulman (2009) to avoid winter pruning and branch stubs of over $60 \mathrm{~mm}$ diameter will likely reduce disease impacts.

\section{Conclusions}

The results of this study clearly indicate that $N$. fuckeliana is present in pruned and unpruned Pinus radiata, suggesting that pruning wounds are not necessary for infection; however, it is not possible to rule out pruning wounds as an infection court. Therefore, successful management of Nectria flute canker disease in Pinus radiata will require a combination of management strategies that include manipulating conditions within a stand to avoid host infection while preventing stress that may promote disease development if the pathogen is already established in the host.

\section{Competing interests}

The authors declare that they have no competing interests.

\section{Authors' contributions}

TR conceptualised and designed the experiment, participated in sample collection, performed preliminary statistical analysis and prepared the manuscript. MP participated in sample collection, conducted all laboratory analyses and participated in manuscript preparation. MK performed the statistical analyses and participated in manuscript preparation. All authors have read and approved the final manuscript.

\section{Acknowledgements}

This work was funded by the New Zealand Foundation for Research Science and Technology (C04X0302) and the New Zealand Forest Biosecurity Research Council. Thank you to City Forests and Wenita Forest Products Ltd. and Peter Oliver and Paul Greaves, respectively, for providing field sites for this work. The technical assistance of Anna Hopkins was greatly appreciated. The manuscript has been improved by comments by Margaret Dick and Rebecca Ganley on an earlier draft of this manuscript.

\section{Author details}

${ }^{1}$ Scion (New Zealand Forest Research Institute Ltd.), Private Bag 3020, Rotorua 3010, New Zealand. 'Current address: Natural Resources Canada, Canadian Forest Service, Northern Forestry Centre, 5320122 St, Edmonton, AB T6H 3S5, Canada. ${ }^{3}$ Current address: Uppsala BioCenter, Department of Forest Mycology and Plant Pathology, Swedish University of Agricultural Sciences, Box 7026SE-750 07, Uppsala, Sweden.

Received: 18 April 2013 Accepted: 5 September 2013

Published: 23 Sep 2013

\section{References}

Bulman, L. (2007). Nectria pruning trial. Forest Health News, 170, 2. http://www. scionresearch.com/_data/assets/pdf_file/0004/3874/FHNewsNo170-Feb07. pdf. Accessed 2 October 2012.

Bulman, L. (2009). Nectria flute canker - a disease almost beaten? Forest Health News, 195, 1-2. http://www.scionresearch.com/_data/assets/pdf_file/0018/ 2781/FHNews195May_June.pdf. Accessed 3 August 2012.

Chou, CKS, \& Mackenzie, M. (1988). Effect of pruning intensity and season on Diplodia pinea infection of Pinus radiata stem through pruning wounds. European Journal of Forest Pathology, 18, 437-444.

Crane, PE, Hopkins, AJM, Dick, MA, \& Bulman, LS. (2009). Behaviour of Neonectrio fuckeliana causing a pine canker disease in New Zealand. Canadian Journal of Forest Research, 39, 2119-2128.

Dick, MA, \& Crane, PE. (2009). Neonectria fuckeliana is pathogenic to Pinus radiata in New Zealand. Australasian Plant Disease Notes, 4, 12-14.

Etheridge, DE, \& Craig, HM. (1976). Factors influencing infection and initiation of decay by the Indian paint fungus (Echinodontium tinctorium) in western hemlock. Canadian Journal of Forest Research, 6, 299-318.

Gadgil, PE, Dick, MA, \& Dobbie, K. (2003). Fungi silvicolae novazelandiae: 4. New Zealand Journal of Forestry Science, 33, 265-272

Gardes, M, \& Bruns, TD. (1993). ITS primers with enhanced specificity for basidiomycetes - application to the identification of mycorrhizae and rusts. Molecular Ecology, 2, 113-118.

Hood, IA, Gardner, JF, Hood, RJ, Smith, BM, \& Phillips, GD. (2009). Pruning and cypress canker in New Zealand. Australasian Plant Pathology, 38, 472-477.

Hopkins, AJM, Dick, MA, Carlson, CA, \& Crane, PE. (2012). Early investigations into the infection courts used by Neonectria fuckeliana to enter Pinus radiata stems. European Journal of Plant Pathology, 132, 537-548.

Huse, KJ. (1981). The distribution of fungi in sound-looking stems of Picea abies in Norway. European Journal of Forest Pathology, 11, 1-6.

Langrell, SRH. (2005). Development of a nested PCR detection procedure for Nectria fuckeliana direct from Norway spruce bark extracts. FEMS Microbiology Letters, 242, 185-193.

Metzler, B. (1997). Quantitative assessment of fungal colonization in Norway spruce after green pruning. European Journal of Forest Pathology, 27, 1-11.

Morales, R. (2009). Deteccion de Neonectria fuckeliana en Chile, asociado a cancros y malformaciones fustales en plantaciones de Pinus radiata. Bosque, 30(2), 106-110.

Neilsen, WA, \& Pinkard, EA. (2003). Effects of green pruning on growth of Pinus radiata. Canadian Journal of Forest Research, 33, 2067-2073.

Roll-Hansen, F, \& Roll-Hansen, H. (1979). Microflora of sound-looking wood in Picea abies stems. European Journal of Forest Pathology, 9, 308-316.

Roll-Hansen, F, \& Roll-Hansen, H. (1980). Microorganisms which invade Picea abies in seasonal stem wounds II. Ascomycetes, Fungi imperfecti, and Bacteria. General discussion, Hymenomycetes included. European Journal of Forest Pathology, 10, 396-410.

Schultz, ME, \& Parmeter, JR, Jr. (1990). A canker disease of Abies concolor caused by Nectria fuckeliana. Plant Disease, 74, 178-180.

Vasiliauskas, R, \& Stenlid, J. (1998). Fungi inhabiting stems of Picea abies in a managed stand in Lithuania. Forest Ecology and Management, 109, 119-126.

Vasiliauskas, R, Stenlid, J, \& Johansson, M. (1996). Fungi in bark peeling wounds of Picea abies in central Sweden. European Journal of Forest Pathology, 26, 285-296.

White, TJ, Bruns, T, Lee, S, \& Taylor, J. (1990). Amplification and direct sequencing of fungal ribosomal RNA genes for phylogenetics. In MA Innis, DH Gelfand, JJ Sninsky, \& TJ White (Eds.), PCR Protocols: A Guide to Methods and Applications (pp. 315-322). New York: Academic Press.

10.1186/1179-5395-43-13

Cite this article as: Ramsfield et al:: The relationship between pruning and the incidence of Neonectria fuckeliana in Pinus radiata. New Zealand Journal of Forestry Science 2013, 43:13 